\title{
Charles-Michel Billard (1800-1832): pioneer of neonatal medicine
}

\section{P M Dunn}

Billard was born in Pellouaille, France, in 1800. He studied medicine, first in Angers and then, between 1824-8, in Paris. During this time he was very poor and supported himself by writing for medical journals and undertaking translations, having learned German, English, and Italian. In 1828, the year he became Docteur en Médecine de la Faculté de Paris, he published his masterpiece Traité des Maladies des Enfants Nouveau-Nés et à la Mamelle. Sadly this brilliant and modest man then contracted phthisis and returned with his wife and child to Angers where he died at the early age of 32 .

Billard's book was the first systematic clinical/pathological text on the newborn infant. Indirectly the fetus was also studied; for, as he wrote:

'During intrauterine life man often suffers many affectations, the fatal consequences of which are brought with him into the world . . . children may be born healthy, sick, convalescent, or entirely recovered from former diseases'.

His experience of newborn infants was based on a year working at the Hospice des Enfants Trouvés in Paris. During that year, 1826, 5392 infants were admitted to the hospital, of which $1404(26 \%)$ died. In passing, it is of interest that Billard mentions that the average weight of the term infant at that time was between $5-51 / 2 \mathrm{lb}$. He describes his clinical/pathological method of approach in the introduction to his book:

'One day in reading Morgagni, a favourite author of mine, I was particularly struck with a passage in the latter part of his forty-eighth epistle. This distinguished observer, after having enumerated the affections to which newborn children are liable, complains of the little progress that has been made in their pathology, and laments with much feeling that mothers, from a false tenderness, constantly oppose the examination of the bodies of their children, the symptoms of whose diseases may have been watched with great carefulness and attention. "How vast and new", says he, "is the space that is still open before us for the study of the diseases of young children!"

Occupying for a year an important station in the Hospice des Enfants Trouvés, in Paris, I observed with close attention the children in that institution and upon the occurrence of a fatal termination of their diseases, I availed myself of the opportunity thus afforded to examine by dissection all their organs, and ascertain the causes and seat of each disease. In

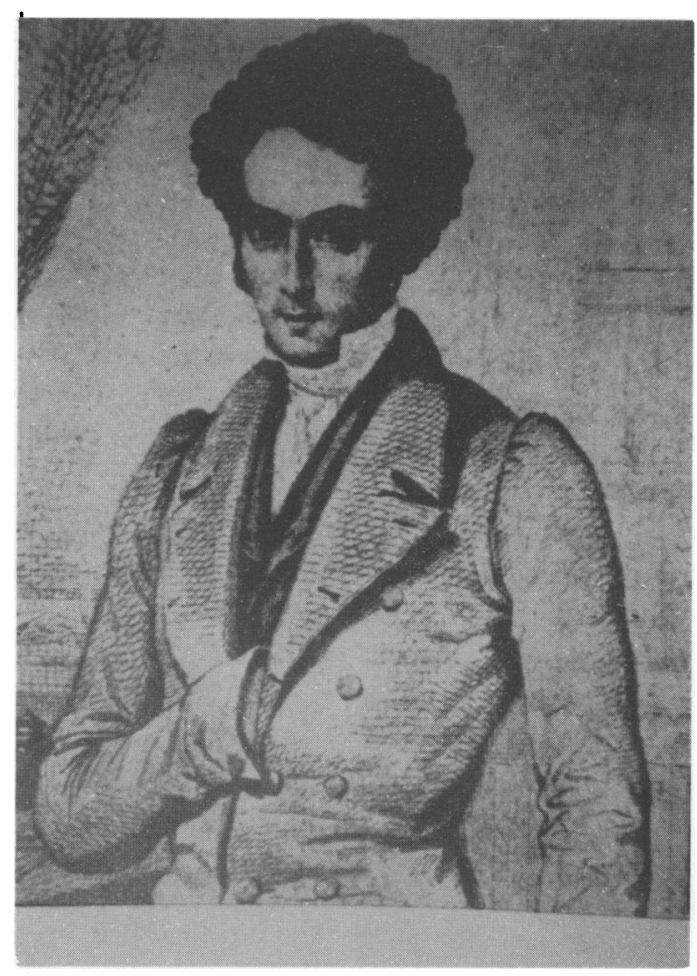

Charles-Michel Billard of France, 1800-1832.

this manner has the wish of Morgagni been fulfilled. I have been able by these means to compare the symptoms observed during life with the anatomical lesions by which they have been produced'.

For the English text of Billard's work we are indebted to Dr James Stewart's translation of the third edition (1837). ${ }^{1}$ The 545 pages are packed with original descriptions and insights which in many instances have been credited to others since his time. The approach is so modern that it may be read with delight and value by anyone with an interest in perinatal medicine. The following few extracts may stimulate others to explore and enjoy this great work:

On a case of congenital urethral atresia

'In this child it appears that the obliteration of the urethra caused the dropsy of the bladder, and the latter, the hydropic affection of the kidneys, the normal development of which was hindered or even suspended ... This case will serve to prove that the excretions of the foetus, at least those of the urinary organs, are, in the normal condition, rejected from the body, and 
probably are mixed with the waters of the amnios, since it appears that when any obstacle occurs to the passage of this fluid, it reflows into the reservoirs, and distends them excessively, in the same manner as is observed in adults who are affected with stricture of the urethra, or paralysis of the bladder. This remark ought to have a place in the history of embryology'.

\section{On nasal respiration}

'It may create some surprise to see the nasal fossae classed with the organs of the respiratory apparatus. In man, the nose and the nasal fossae are but an accessary part, and one not immediately dependent on the respiratory system; they are especially destined to olfaction. In some animals, and particularly among fishes, the nasal fossae are altogether separated from the respiratory passages; but this is not the case with an infant at birth; it respires very little by the mouth, which is almost always shut, and while sucking, it is essentially necessary that the air penetrate the lungs through the nasal fossae, since the buccal cavity, applied to the nipple, is continually filled with milk. Besides, without this it would be impossible to prolong the act of sucking for any length of time'.

\section{On primary atelectasis}

'It is not usual to meet with so complete an absence of air in the lungs of infants, who, like the one just mentioned, live for some time, as it were, the embryo life, either because the blood preserves its vivifying principle which it received from the mother, or that the oxygen of the air absorbed by the skin or mucous membranes penetrated into the circulation, or that this essential element of life is not at this time of so great importance as it is afterwards'.

\section{On imperfect establishment of respiration}

'... the air sometimes passes freely into the lungs at the period of birth, but the sanguineous congestion which occurs immediately expels it or hinders it from penetrating in sufficient quantity to effect a complete establishment of life. There exists, as is well known, between the circulation and respiration, an intimate and reciprocal relation, which is evident during life, but more particularly so at the time of birth ... The symptoms of pulmonary engorgement in an infant are, in general, very obscure, and consequently difficult of observation; yet we may point out the following: the respiration is laboured; the thoracic parietes are not perfectly developed; the face is purple; the general color indicates a sanguineous plethora in all the organs; the cries are obscure, painful, and short; percussion yields a dull sound'.

\section{On jaundice of the brain}

'I have remarked the yellow colouring which constitutes jaundice, in four instances, in the brain and spinal marrow; the brain, which was of moderate firmness, presented a uniform and bright yellow in two of these subjects, while the color was in isolated patches in the other two. In three of these cases the substance of the medulla was of a deep yellow, and its consistence very soft; and in the two subjects where the yellow color of the brain was uniform, there existed, at the same time, a general jaundiced affection of the skin'.

\section{Of the attitudes of the child}

'If the child, immediately after birth, and while the accoucheur is engaged in tying the umbilical cord, be allowed to remain in the situation in which it was expelled from the uterus, it will be observed that a flexion of its members takes place, the head and breast approximate, the body rolls upon itself, and assumes a posture somewhat similar to that it had while within the womb . . . In a word, the flexed position of the limbs and the forward curvature of the trunk, constitute the peculiar position of a newly born infant'.

\section{Of the colour of the skin}

'Infants recently born, are almost all of the same color. Blood predominates in their tissues and communicates, to them its hue and the face, body, and limbs are all strongly colored . . . If it continues, it is not so intense as at first; it becomes of a violet hue, and the hands and feet more particularly exhibit this change of color . . . When the finger is applied to the skin of an infant, the red color disappears at this point, and it becomes yellowish; afterwards the blood returns by degrees in the capillaries from which the pressure had removed it, and the yellow tint is replaced by the previous red. It will often be observed, after the red color has disappeared, and before it becomes altogether white, that the skin will exhibit a universal tint of yellow, and sometimes of a copper color. This is thought, by physicians generally, to indicate an affection of the liver'.

1 Billard CM. A treatise on the diseases of infants with a disserta tion on the viability of the child. Translated by James Stewart, MD. London: John Churchill, 1839. 